\title{
Comprehensive Measurement of the Deformation and Failure of Floor Rocks: A Case Study of the Xinglongzhuang Coal Mine
}

\author{
Hao Liu, ${ }^{1}$ Pu Wang $\mathbb{D}^{2}$ Weihe Zhang, ${ }^{3}$ Qiang Liu, ${ }^{3}$ and Lijun $\mathrm{Su}^{3}$ \\ ${ }^{1}$ College of Energy and Mining Engineering, Shandong University of Science and Technology, Qingdao 266590, China \\ ${ }^{2}$ College of Resources, Shandong University of Science and Technology, Tai'an 271019, China \\ ${ }^{3}$ Yanzhou Coal Mining Co. Ltd., Yankuang Group, Xingloangzhuang Coal Mine, Jining, 272102 Shandong, China
}

Correspondence should be addressed to Pu Wang; 15854848872@163.com

Received 15 August 2020; Revised 4 September 2020; Accepted 15 October 2020; Published 12 November 2020

Academic Editor: Hualei Zhang

Copyright (c) 2020 Hao Liu et al. This is an open access article distributed under the Creative Commons Attribution License, which permits unrestricted use, distribution, and reproduction in any medium, provided the original work is properly cited.

\begin{abstract}
The isolated island panel 10304 of the Xinglongzhuang coal mine was used as the research subject to study the deformation and damage characteristics of the coal seam floor. The damage of the floor was studied using the borehole strain sensing method and borehole imaging technology, and FLAC3D was used to study the influence of abutment pressure on floor failure. The result shows that the floor under the superimposed area which is affected by lateral and advanced abutment pressure is damaged firstly, and the maximum depth reaches $26 \mathrm{~m}$, other areas of the working face about $23 \mathrm{~m}$. The degree of deformation and failure of floor rock at different depths is decreased. The deformation damage increases with the advancement of the working face until a certain distance at the same depth. The hole image can clearly show the influence range of the abutment pressure in front of the coal wall and influence the degree of the advancement and lag by means of the strain increment curve for each sensor probe and the images from different drilled positions. On the basis that the results of simulation and field measurement are consistent, the results can reflect the three-dimensional failure characteristics of the whole island working face floor in the process of coal mining more comprehensively and accurately; moreover, they also can provide important information for mine flood prevention and ecological environment protection.
\end{abstract}

\section{Introduction}

Mine water inrush accidents not only destroy the underground construction environment but also threaten the safe production of coal mines, and coal seam floor water inrush is a common type of coal mine water inrush accident [1-3]. When a coal seam is mined, the abutment pressure shifts to the deep part of the floor, causing deformation and damage within a certain range of the underlying strata of the floor [4-8]. A water inrush accident will happen if the floor damage zone communicates with the underlying aquifer when there is an aquifer in the underlying strata of the floor. Therefore, it is of great significance and practical application value to grasp the failure and deformation law of coal seam floors and determine the damage depth of the floors to guide safe coal mine production $[9,10]$.

In recent years, many scholars have studied the damage characteristics of coal seam floors and obtained many research results. At present, the research methods for the deformation and failure characteristics of the floor can be divided into three types, theoretical analysis and calculation methods, indoor simulation test methods, and software simulation methods. As for theoretical analysis and calculation methods, Cai et al. [11] regarded the rock mass of a floor as a semi-infinite uniform medium and, according to the law of abutment stress, proposed an analytical estimation formula for the maximum mining failure depth of the floor for a circular arch structure of overburden strata. Shi et al. [12] analyzed the influencing factors of multiple floor failures, and a multivariate linear regression analysis method was used to fit the nonlinear regression formula for predicting the depth of the damage of the floor. Liu et al. [13], who established a mechanical model for the failure degree of a floor based on the theory of elastic mechanics, used the matrix analysis method and the analysis of variance to determine the sensitivity of each main control factor on the depth 
of damage of the floor. Yu et al. [14] analyzed the factors affecting the depth of floor failure, and the BP neural network was used to establish a prediction model for the depth of the floor failure. However, due to the complicated underground conditions, the theoretical calculation results are often not sufficiently accurate.

For indoor simulation test methods, Liu et al. and Song et al. [15-17] performed similar indoor simulations to analyze the failure deformation of the floor during the mining process. This method has high requirements for laboratories and is not widely used. For software simulation methods, Cai et al. and Zhu et al. [18-20] used FLAC3D and UDEC software. These two numerical simulation software programs are used to simulate the failure deformation of floors during mining. However, the deformation and failure characteristics of the floor are related to many factors, such as mining depth, working face size, water pressure, cohesion, and friction angle; the software simulation often fails to accurately grasp the actual situation on-site.

Compared with the above methods, the field measurement method is the most reliable and effective method to reveal the deformation and damage of the mining floor. The damage depth of the floor can be measured by various methods. At present, the most common methods are the borehole water injection method, borehole acoustic wave method, borehole imaging method, and borehole strain method [21-26]. The borehole water injection method and the borehole acoustic wave method arrange measuring points on both sides of the coal roadway and carry out comparative tests before and after the mining of the measuring points. Most of the roadways after mining are damaged under normal mining conditions unless special safeguard measures are taken. It is difficult to conduct comparison tests at the original points (measuring points before mining), and most of the measuring point data before mining is in the vicinity of the measuring point at present [27-30]. Since the deformation of the floor has a certain hysteresis with respect to the advancement of the working face, the deformation of the floor can reach a sufficient degree after the working face is advanced. Therefore, the reliability of the data obtained by these methods is relatively low. Compared with the borehole strain method, strain gauges at different depths of the floor can be used to continuously monitor the deformation of the floor during the mining process. According to the test data, the range of influence of the mining pressure and the stress concentration in front of the coal wall can be determined, and the test data of the probes at different depth positions can reflect the difference in the vertical deformation of the floor and thus determine the depth range of the floor failure.

Therefore, to study the deformation and failure law for the floor of the island face in the Xinglongzhuang coal mine and to determine the depth of the floor failure, this test used the borehole strain sensing method and borehole imaging technology to obtain the floor stratum disturbance and reliable data on characteristics and the depth of damage during the mining process. This study provides a reliable basis for safe mining of coal mines.

\section{Engineering Background}

The Xinglongzhuang coal mine of Shandong Province is located in North China. According to the drilling data of the mine, the minefield strata are Quaternary, Jurassic, Permian, Carboniferous, and Ordovician from the top to the bottom, among which the Carboniferous Permian system (C-P system) is the main coal-bearing strata. Panel 10304 employed longwall mining with the top coal caving method. The No. 3 seam was mined with a thickness of approximately $8.9 \mathrm{~m}$ and a dip angle of approximately $8^{\circ}$. The horizontal elevation of the working face is $-550 \sim-380 \mathrm{~m}$, the ground elevation is approximately $47 \mathrm{~m}$, the working face is $2200 \mathrm{~m}$ long, and the width is approximately $200 \mathrm{~m}$. Both sides of the 10304 working face have been mined out. The direct floor of the No. 3 seam is mudstone, and the main floor is sandstone. There is a confined aquifer in the minefield, which is located under the No. 3 seam floor, $28 \sim 46 \mathrm{~m}$ away from the No. 3 seam floor, with an average length of $36 \mathrm{~m}$ The average thickness of the aquifer is $5.2 \mathrm{~m}$, the capacity of the water inflow is $0.018 \sim 0.26 \mathrm{~L} / \mathrm{s} \cdot \mathrm{m}$, and the highest water pressure is $5.8 \mathrm{MPa}$. Because the aquifer is close to the floor of the 10304 working face and the water pressure is large, the water inrush from the floor of the 10304 working face cannot be ignored. Figure 1 shows the hydrogeological and comprehensive column diagram of the No. 3 seam under the minefield. Because of the heavy abutment pressure of the island working face, the close distance between the floor of the 10304 working face and the aquifer, and the huge hydraulic pressure, the water inrush from the floor of the 10304 working face cannot be ignored.

\section{Field Strain Measurement}

3.1. Strain Test. The borehole strain test method involves burying the strain sensor probe at different depths of the working face by means of drilling and determining the degree of influence and depth of the floor by testing the degree of deformation of the rock strata at the position of the measuring points of the floor during the mining process. This type of probe [31] is sensitive to the deformation of the surrounding rock, and the degree of deformation of the surrounding rock can be visualized by the probe test data. When the working face is far from the probe position, the test data of the probe are relatively stable such that the mining pressure has not reached the measuring point. When the mining pressure is applied to the measuring points, the probe test data will change synchronously with the degree of influence.

Figure 2 shows the internal structure of the strain probe. Each strain probe has two axial strain points and two radial strain points. The outer wall of the probe is made of highelastic plastic material, which is evenly stressed, has high elastic sensitivity, and has good sensitivity to damage and deformation. It should be noted that when the test hole is severely deformed, which will cause the outer wall of the probe to be severely twisted or damaged, the test data may exhibit high dispersion, disordered fluctuations, or even failure (the strain gauge has no reading). Therefore, the abnormal condition 


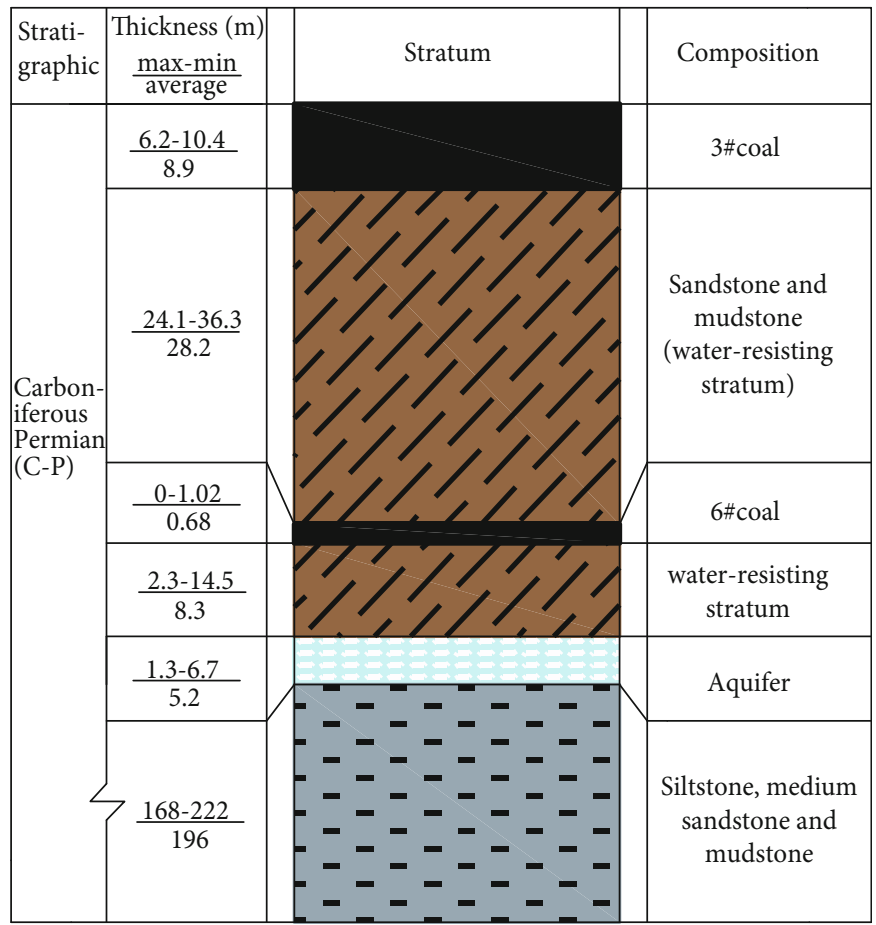

FIGURE 1: Comprehensive column diagram of the hydrogeology of the underlying strata.

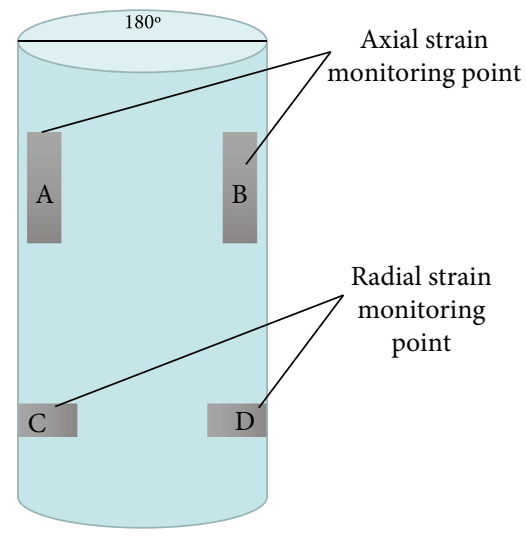

FIGURE 2: Schematic diagram of the strain probe.

described above can also reflect the destruction of the floor stratum formations.

3.2. Borehole Imaging Method. Borehole imaging observation is a testing technique that allows the visualization of rock formations. In the floor borehole, the sliding rod is connected to the imaging probe, and the rock stratum structure image of the borehole hole wall of the working face is obtained by stretching and retracting the sliding rod. The degree of influence of mining on different depths of the rock strata under the floor is determined by observing the change in the rock structure of the drilling hole wall in the process of mining.

3.3. Layout of Measuring Points. According to the actual and test conditions of the 10304 panel, the observation hole is arranged in the roadway of the lower panel. The elevation of the roadway is $-449 \mathrm{~m}$, the vertical height of the distance from the No. 3 seam is $41 \mathrm{~m}$, three measurements are arranged, and holes 1 and 2 are strain test holes. Hole 3 is the imaging observation hole, as shown in Figure 3.

Considering the position of the aquifer in the lower part of the 10304 panel and referring to the existing empirical data of the floor breaking depth $[32,33]$, the test range for the destruction and deformation of the mining floor is controlled to a depth of approximately $30 \mathrm{~m}$ at the underlying distance of the coal seam. A schematic diagram of the drilling arrangement and floor rock formation is shown in the figure as follows.

As shown in Figure 4, the 1st and 2nd strain measuring boreholes are set up with 5 strain sensor probes. The topdown measuring points in the No. 1 test hole are 1-1, 1-2, $1-3,1-4$, and 1-5. The vertical heights from measuring points from the coal seam floor are $5.4 \mathrm{~m}, 12.6 \mathrm{~m}, 17.3 \mathrm{~m}, 24.1 \mathrm{~m}$, and $29.8 \mathrm{~m}$, respectively. The top-down measuring points in the No. 2 test hole are 2-1, 2-2, 2-3, 2-4, and 2-5. The vertical heights from measuring points from the coal seam floor are $6.2 \mathrm{~m}, 13.8 \mathrm{~m}, 20.1 \mathrm{~m}, 25.3 \mathrm{~m}$, and $30.2 \mathrm{~m}$, respectively.

According to the mining and geological conditions of the working face, there are no faults or other special structures between the strain test hole and the imaging observation hole. Accordingly, the design parameters of the imaging observation hole and the strain test hole are the same, and the drilling parameters are shown in Table 1.

3.4. Observation Methods. Considering that panel 10304 is fully mechanized for caving mining in thick coal seams and that the working face is an island working face, the mining stress is concentrated and the influence range is wide [34, 35]. The strain test range is designed to be $230 \mathrm{~m}$, of which the advanced range is $150 \mathrm{~m}$. The lagging range is $80 \mathrm{~m}$, and 


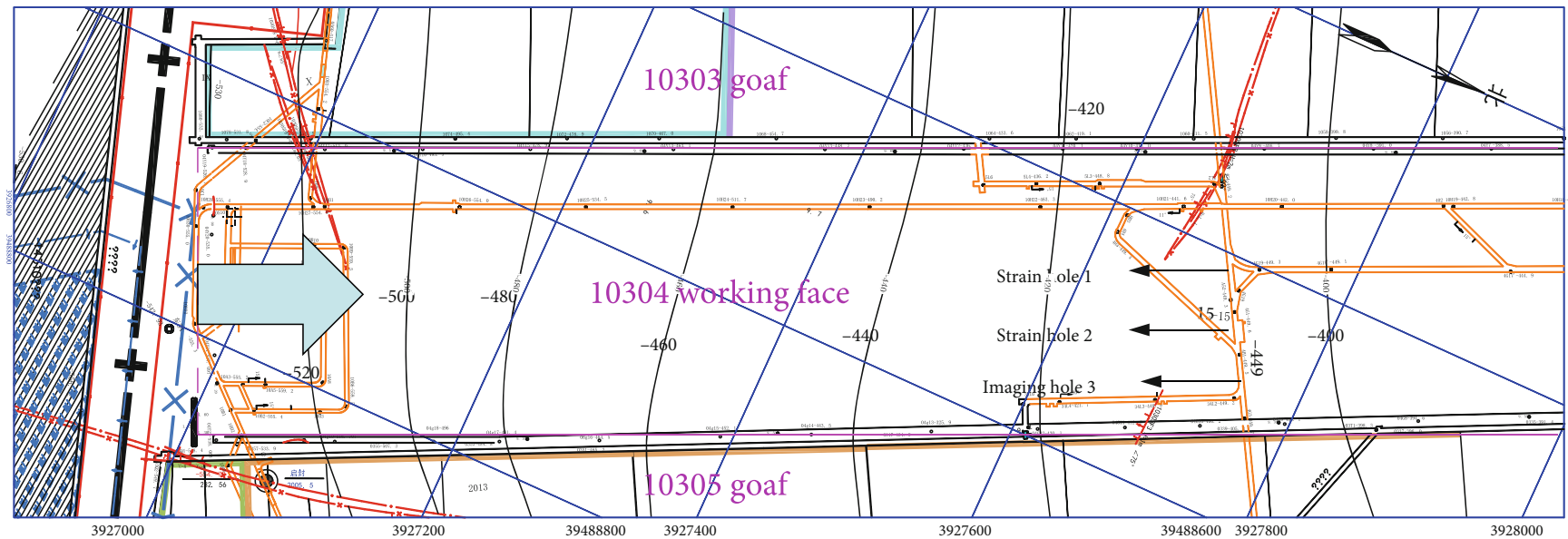

FIGURE 3: Panel 10304 borehole layout.
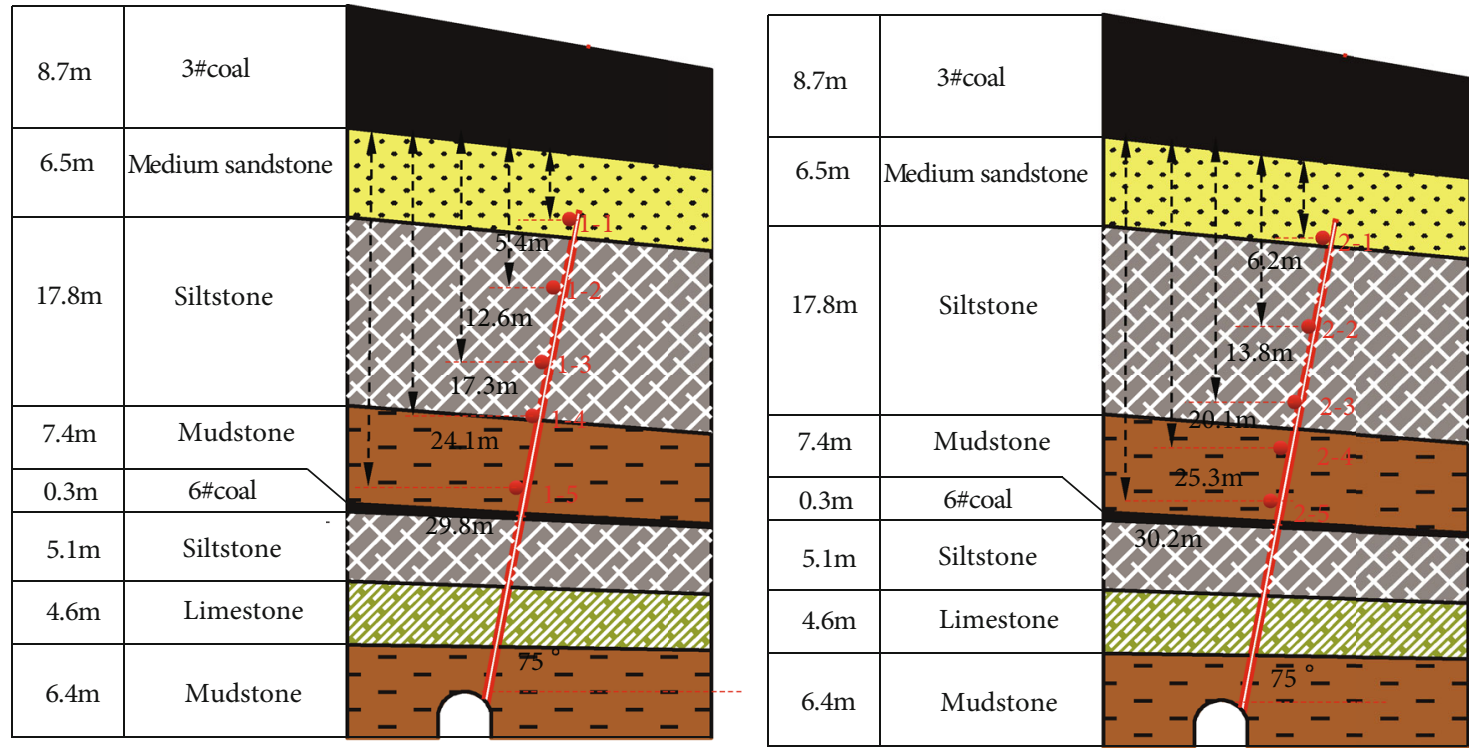

FIGURE 4: Layout of strain boreholes.

TABLE 1: Design parameters of the boreholes.

Borehole parameters

Opening diameter $(\mathrm{mm})$

Diameter (mm)

Borehole elevation angle $\left({ }^{\circ}\right)$

Angle between the drilling hole and the strike line of the coal and rock seam

the mine pressure induction and deformation of the measuring point in the recovery process are tested. For the observation frequency, the measurement is started when the distance between the end face and the test borehole is $150 \mathrm{~m}$. When the distance between the end face and the test hole is $150 \sim 90 \mathrm{~m}$, a set of data is measured every $20 \mathrm{~m}$ of the advancement of the working face. When the distance between the end face and the test hole is $90 \sim 60 \mathrm{~m}$, a set of data is measured every $15 \mathrm{~m}$ of the advancement of the work- ing face. When the distance between the end face and the test hole is $-40 \sim 60 \mathrm{~m}$ ("-” represents advancing past the measuring point), a set of data is measured every $10 \mathrm{~m}$ of the advancement of the working face. When the distance between the end face and the test hole is $-80 \sim-40 \mathrm{~m}$, a set of data is measured every $20 \mathrm{~m}$ of the advancement of the working face. To avoid an abnormal situation during the test, three sets of data are measured for each observation. The interval between each set of data is approximately 30 


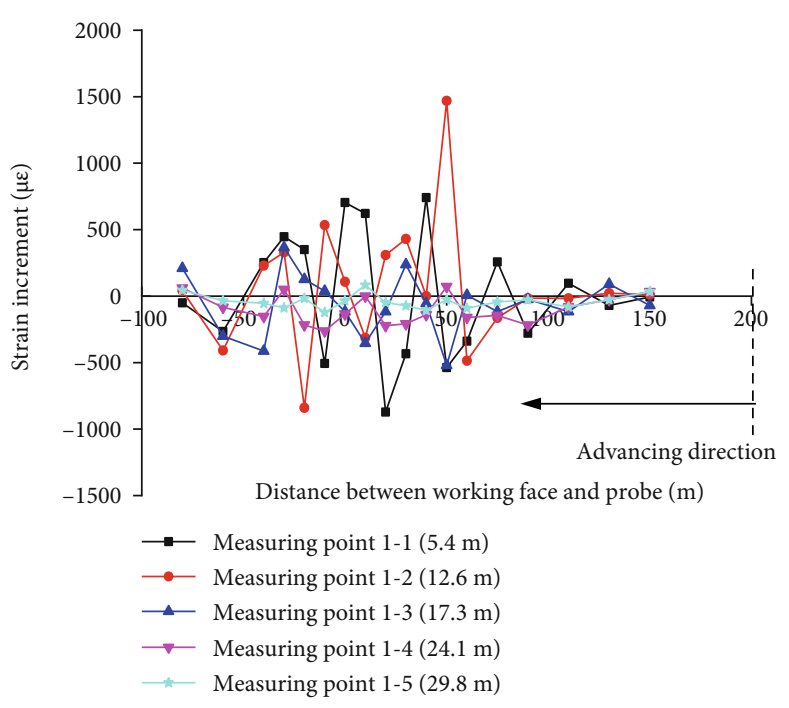

(a) Axial strain measured by gauge a

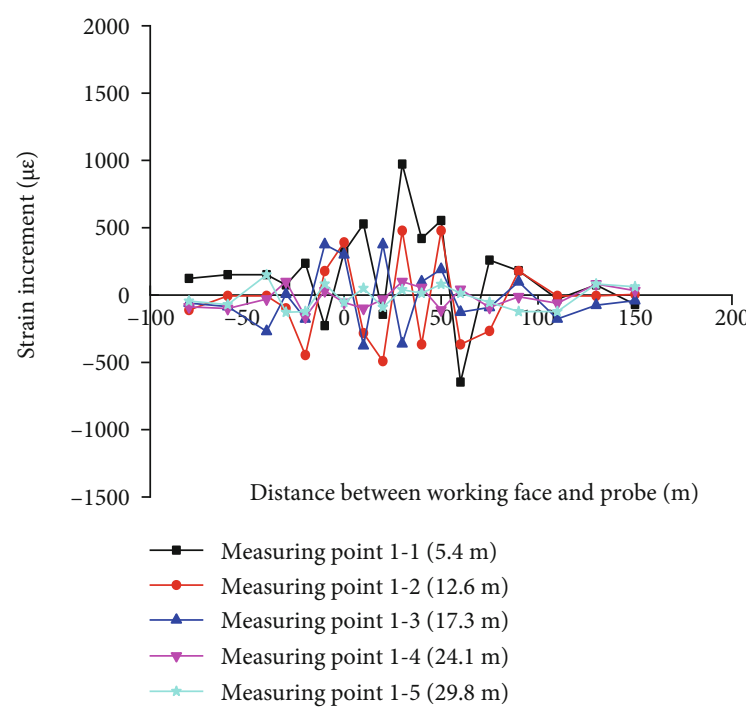

(c) Radial strain measured by gauge $c$

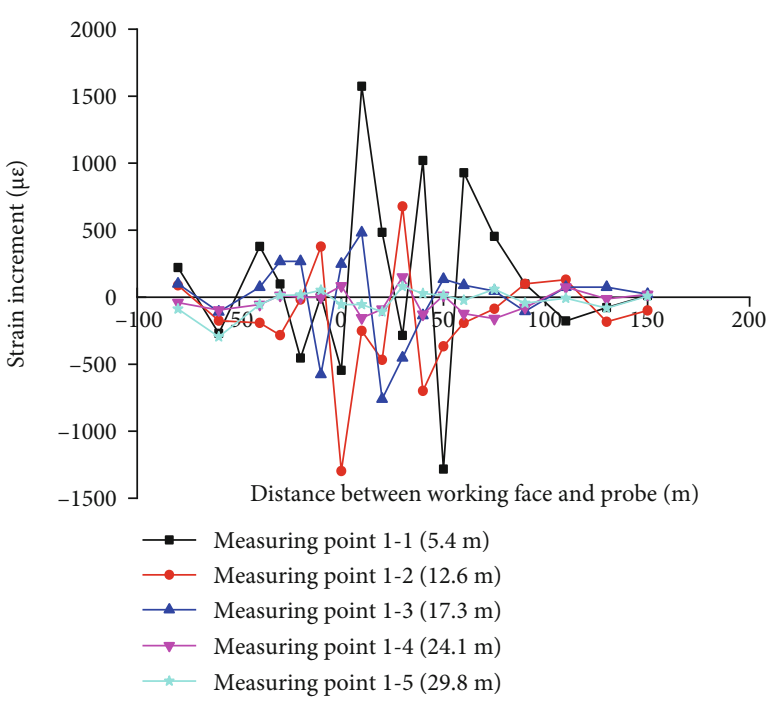

(b) Axial strain measured by gauge $b$

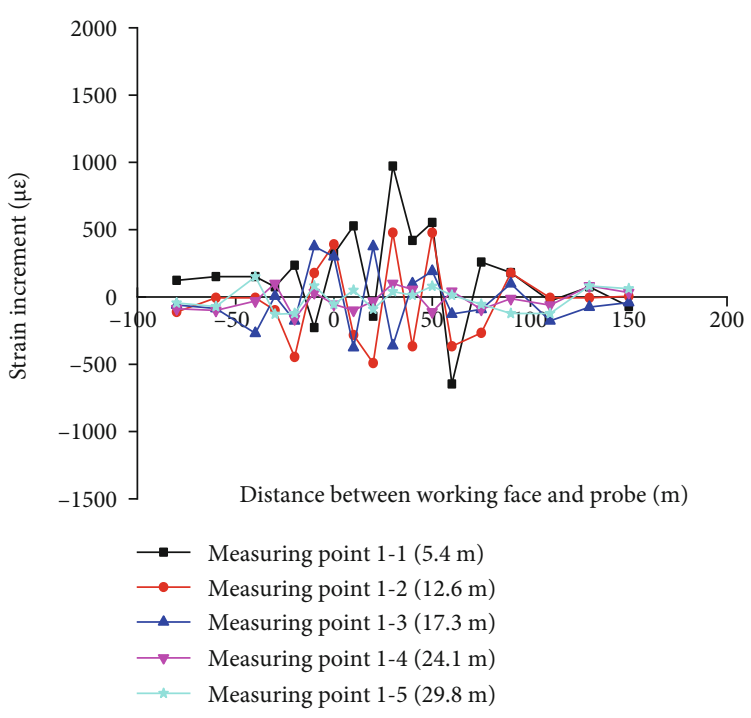

(d) Radial strain measured by gauge $\mathrm{d}$

Figure 5: The increment of axial strain and radial strain of the No. 1 hole.

minutes, and the average value is taken as the corresponding observation result.

\section{Result Analysis of Field Observations}

4.1. Result Analysis of the Strain Observation. In this paper, the strain is measured by the strain sensors which each has four strain gauges marked as a, b, c, and d. Among them, gauges $\mathrm{a}$ and $\mathrm{b}$ measure the axial strain, while gauges $\mathrm{c}$ and $\mathrm{d}$ measure the radial strain. However, during the process of actual measurement, abnormal points of strain response (corresponding to large discreteness) may appear, which is caused by the serious deformation, fracture, or rock outburst of the hole wall, thereby resulting in serious damage of the sensors; hence, these abnormal points should be removed [36]. Figures 5 and 6 depict the strain increment of the aforementioned four sensors in two borehole positions marked as Nos. 1 and 2.
In Figures 5 and 6, it can be seen that all the measuring points show the obvious advances and delay induction caused by the stratum behaviors during the mining process. For instance, when the distance between the face and the measuring holes is approximately $100 \mathrm{~m}$, obvious strain appears successively at the measuring points, and it still exists with the advance exceeding $80 \mathrm{~m}$, which indicates that the large range of floor is affected by mining activities.

Moreover, the strain response range for different depth measurement points is different. In Figure 5, the strain sensing range of 1-1-1-5 measuring points depicts $100 \sim-80 \mathrm{~m}$, $80 \sim-80 \mathrm{~m}, 60 \sim-80 \mathrm{~m}, 50 \sim-80 \mathrm{~m}$, and $50 \sim-80 \mathrm{~m}$. And the results of the No. 2 borehole (shown in Figure 6) are similar to those of the No. 1 measuring hole, indicating that the influence range is affected by mining gradually from shallow to deep.

Compared with the measuring points with shallow positions of Figures 5 and 6 , the strain increment and strain 


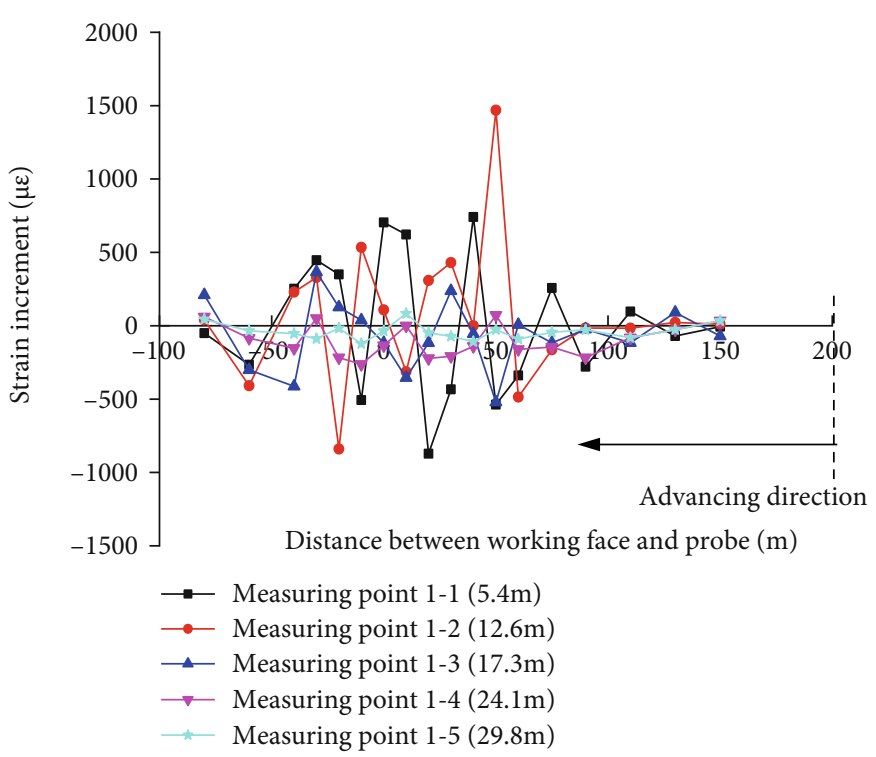

(a) Axial strain measured by gauge a

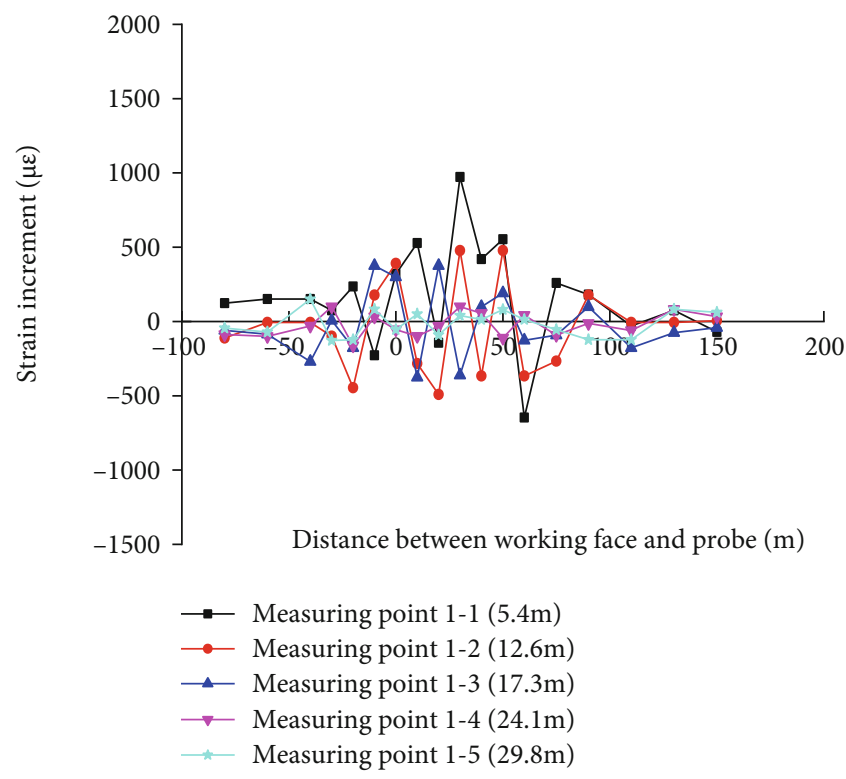

(c) Radial strain measured by gauge $c$

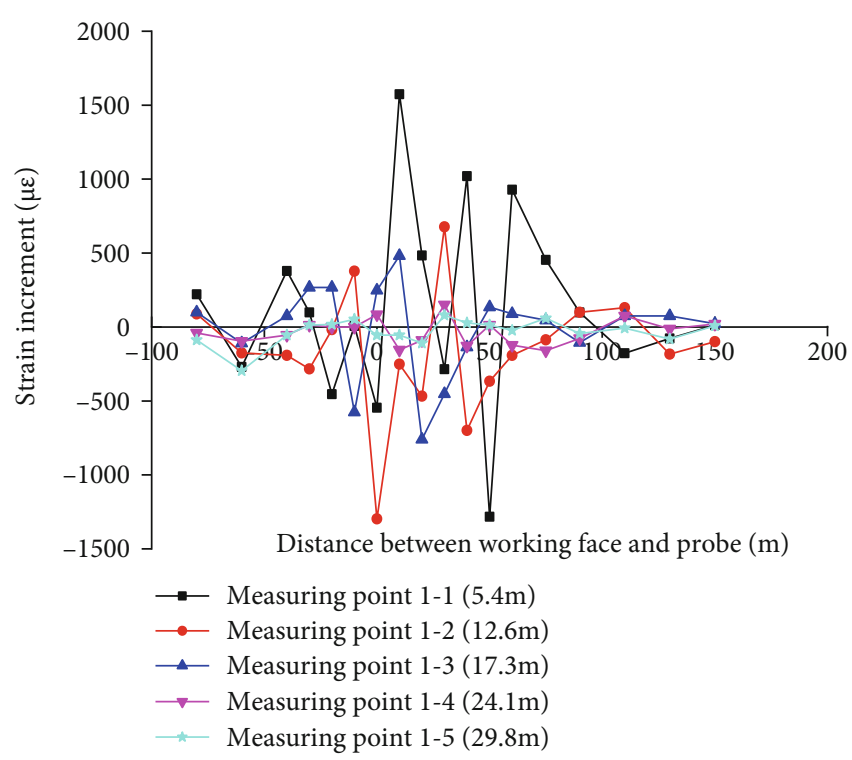

(b) Axial strain measured by gauge $\mathrm{b}$

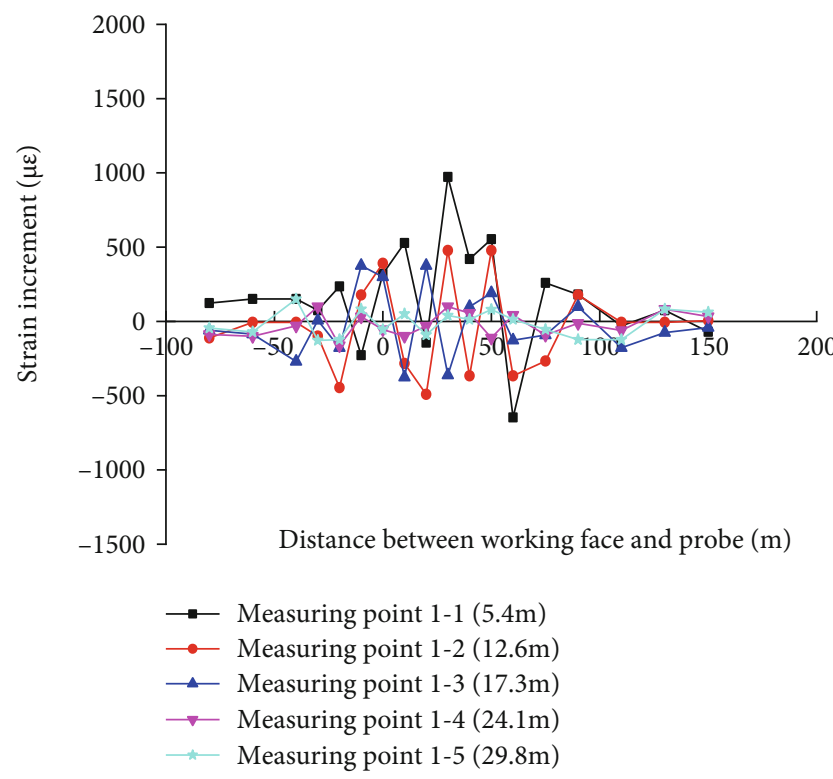

(d) Radial strain measured by gauge $\mathrm{d}$

Figure 6: The increment of axial strain and radial strain of the No. 2 hole.

fluctuation amplitudes of these deep measuring points (1-4, $1-5,2-4$, and 2-5) are relatively small, showing that the mining disturbances in the surrounding rock of the deep measuring points are mainly elastic waves and the rock does not have a large plastic deformation. Considering that the buried depth of measuring points $1-4$ and $2-4$ is $24 \sim 25 \mathrm{~m}$ from the coal floor, the elastic characteristics of the strain respond obviously, which is in sharp contrast with the straininduced anomaly with overlying measuring points. Therefore, both measurement points and the following locations are not destroyed by the mining pressure, so it can be determined that the floor failure depth is approximately $24 \mathrm{~m}$ during the mining process of panel 10304.

From the strain response of the measuring points, the strain response of all the measuring points shows an obvious axial strain and weak radial strain. Since the test hole is arranged at a large elevation angle, the axial direction of the sensors is similar to the normal direction of the rock strata, and the radial component of the pressure is small, resulting in a weak strain. This indicates that the force of the sensors is mainly due to axial compression and axial extension, the radial force is weak, and the corresponding deformation of the floor is similar to the compression or tension that is close to the normal direction of the rock strata.

4.2. Imaging Observation Results. To obtain the necessary contrast basis, the observation is carried out when the distance between the face end and the imaging observation hole is $150 \mathrm{~m}, 38 \mathrm{~m},-16 \mathrm{~m}$, and $-60 \mathrm{~m}$, and four sets of video data at different stages of the imaging observation hole are 


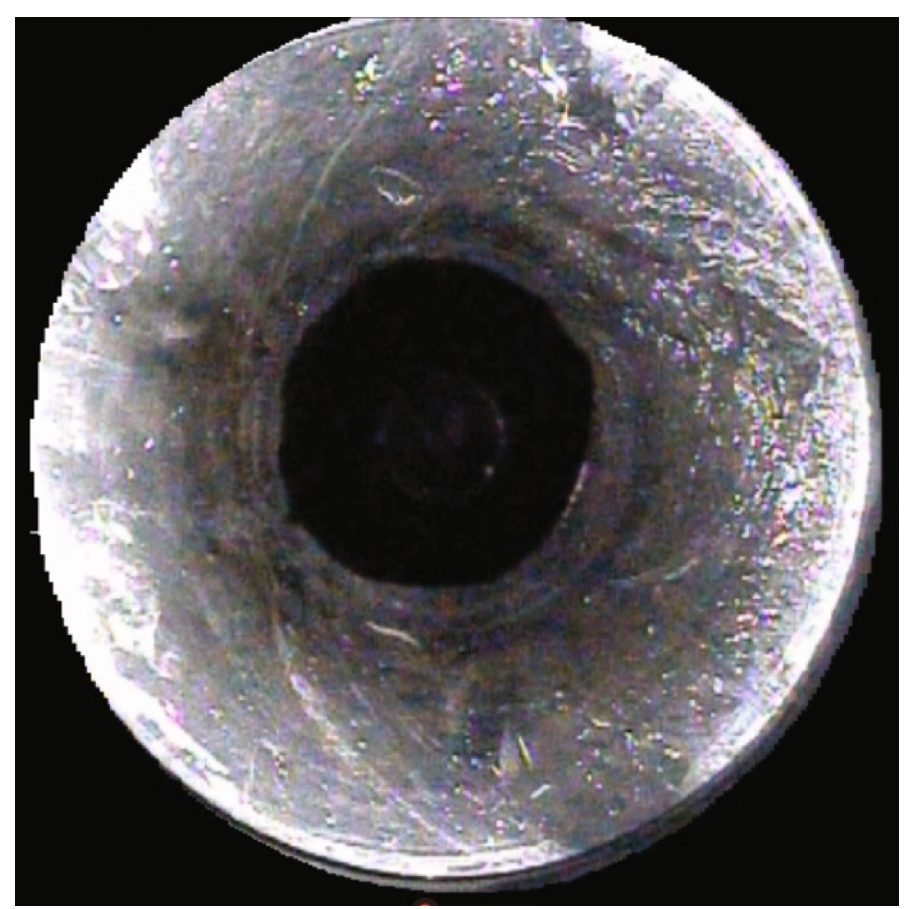

(a) $L=156 \mathrm{~m}$

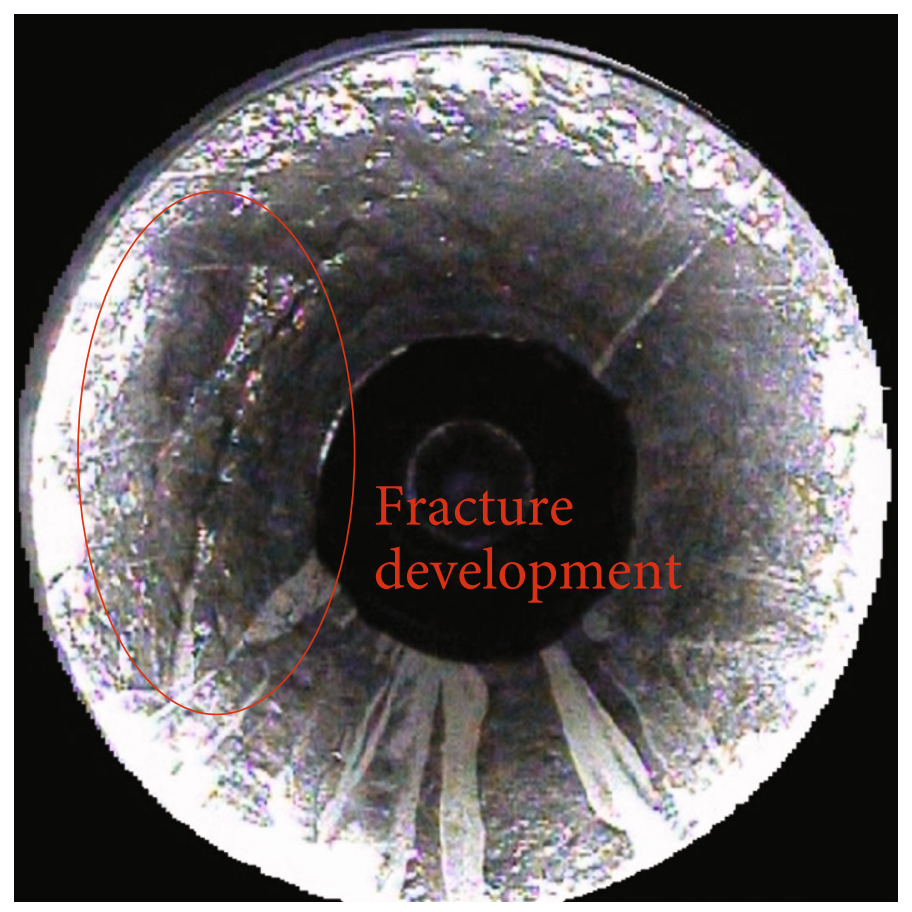

(b) $L=38 \mathrm{~m}$

Figure 7: Continued. 


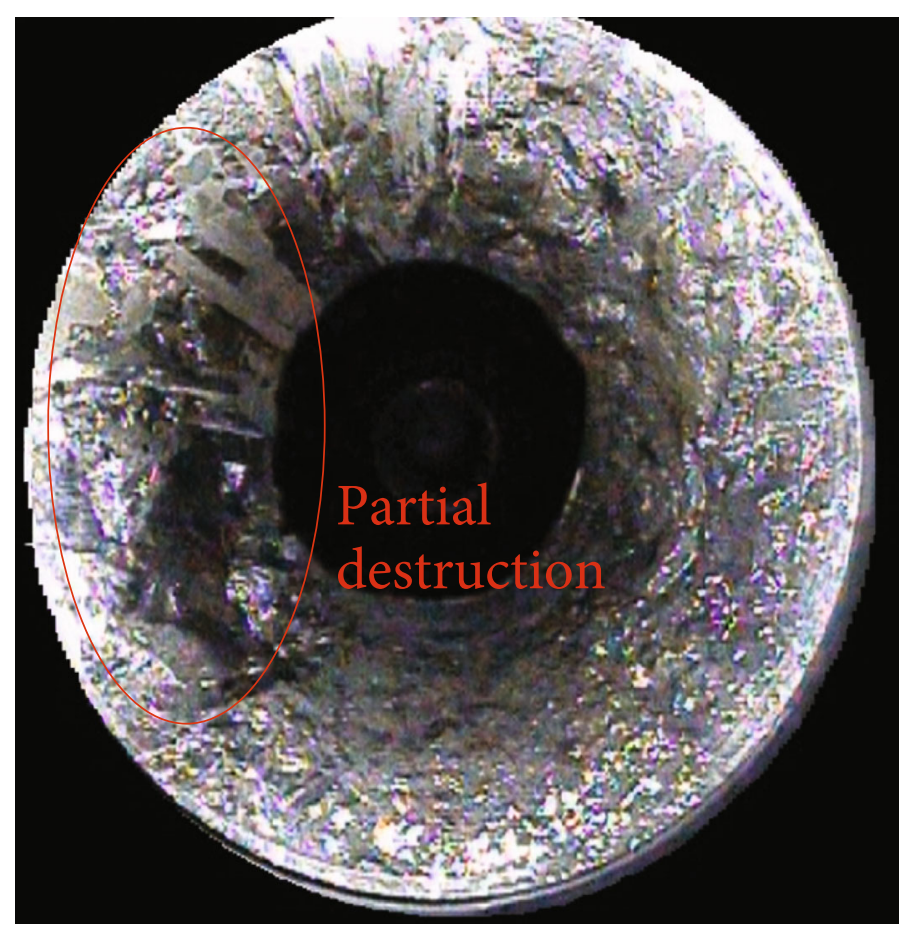

(c) $L=-16 \mathrm{~m}$

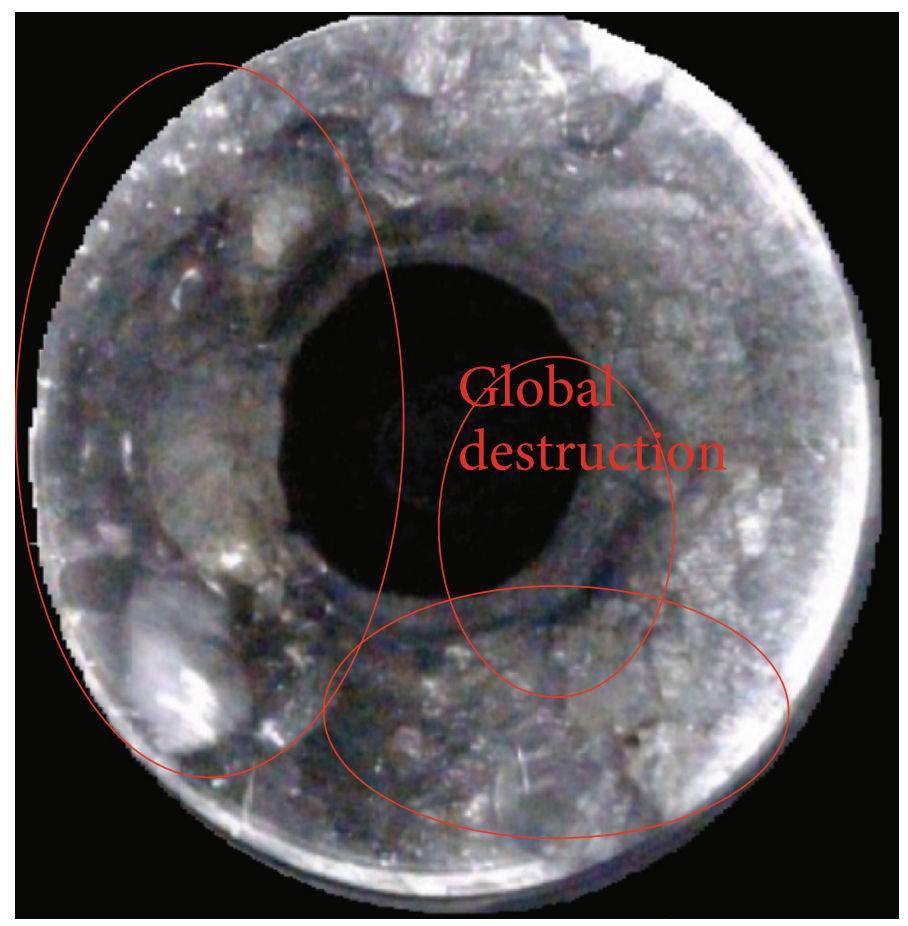

(d) $L=-60 \mathrm{~m}$

Figure 7: Image of the damage and deformation at a vertical depth of $10-11 \mathrm{~m}$ (" $L$ " is the distance from the face end to the measuring hole).

obtained. Due to the limited space of the article, only three observation results are given here, which are $10-11 \mathrm{~m}, 22-$ $23 \mathrm{~m}$, and $26-27 \mathrm{~m}$ (Figures 7-9) from the vertical depth of the floor. These results show the deformation and failure of the borehole wall during the mining process.

It is clear from Figures 7-9 that with the advancement of the working face, the wall of the hole $10 \sim 11 \mathrm{~m}$ from the floor has gone through four stages: completion, fracture development, partial destruction, and global destruction. These stages reflect the gradual destruction process of the wall of the hole at shallow depths. There is local deformation damage to the hole of the wall at a depth of 22 23 $\mathrm{m}$ (Figure 8), and the floor depth is $26 \sim 27 \mathrm{~m}$. There is no obvious trace of disturbance deformation, which indicates that the degree of 


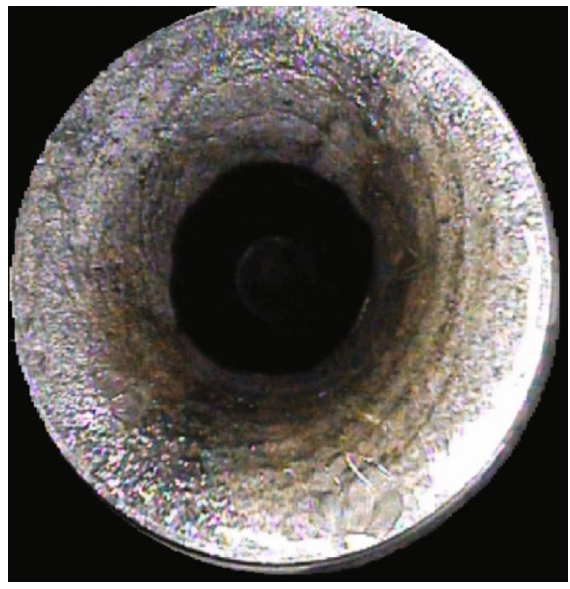

(a) $L=156 \mathrm{~m}$

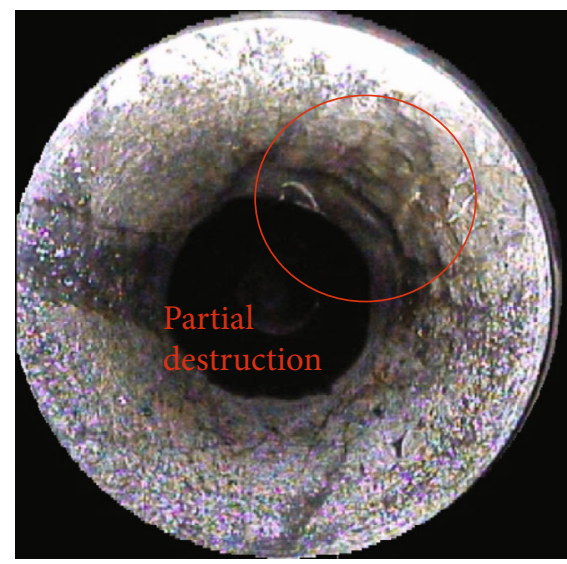

(c) $L=-16 \mathrm{~m}$

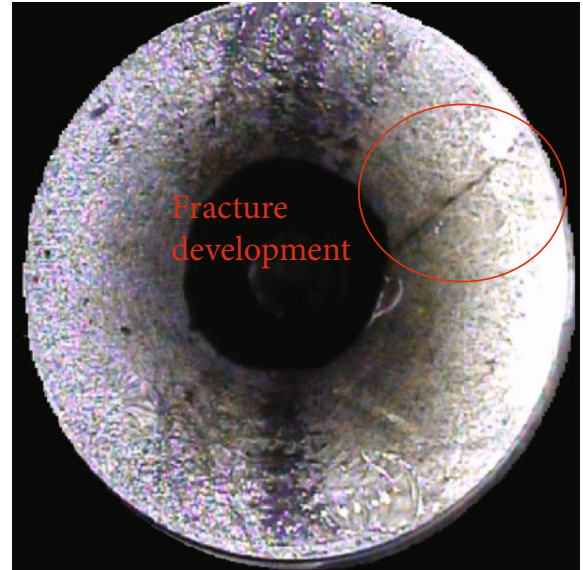

(b) $L=38 \mathrm{~m}$

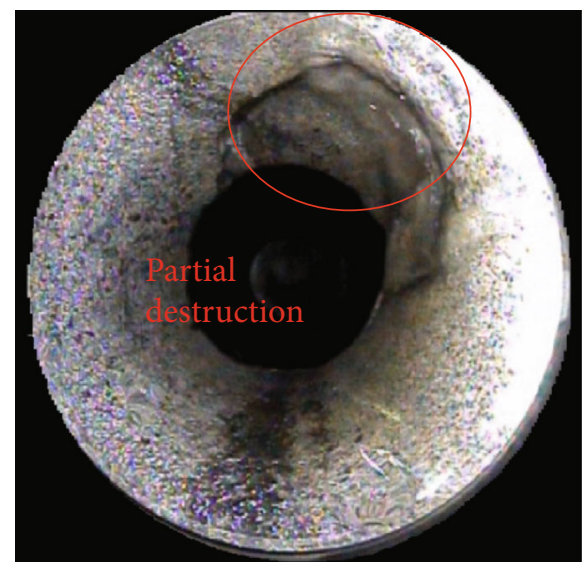

(d) $L=-60 \mathrm{~m}$

FIGURE 8: Image of damage and deformation at the vertical depth of 22-23 m.

deformation and failure of the rock mass at different depths during the advancement of the working face decreases with increasing depth.

According to the observation results, it is found that the degree of deformation of the surrounding rock of the hole is essentially changed at a floor depth of $23 \mathrm{~m}$, which is not much different from the above strain test results. Based on the correlation analysis between the strain test results and the borehole imaging, the depth of the mining disturbance of panel 10304 can be determined to be approximately $23 \mathrm{~m}$. Among them, the rock strata in the range of $0 \sim 23 \mathrm{~m}$ in the vertical depth of the floor are damaged by mining, mainly due to plastic deformation, and the range of plastic displacement is large. The rock strata below the failure zone are affected by mining, which is mainly due to elastic deformation, and it has a good bearing capacity and strong impermeability based on the intact structure results.

\section{Numerical Simulation of Failure Characteristics of Floor Rocks}

In order to explain the failure law of floor rock in panel 10304 well, FLAC3D numerical simulation software is used to simulate the development of the floor plastic zone. The model with $400 \times 300 \times 128$ is built according to actual conditions, as shown in Figure 10. Both sides of the working face are filled goaf, and the direction $y$ is advanced direction. The monitoring plane is arranged at the position of $y=100 \mathrm{~m}$. The Mohr-Coulomb constitutive model and MohrCoulomb failure criterion are used to calculate the mining failure characteristics of the coal seam floor. The geomechanical parameters of each stratum are shown in Table 2.

Figure 11 shows the development of the plastic zone of a plane with $y=100 \mathrm{~m}$ and the distribution of abutment stress of floor rock depicted in the monitoring plane when the island face advances to $10 \mathrm{~m}, 50 \mathrm{~m}, 70 \mathrm{~m}, 90 \mathrm{~m}, 110 \mathrm{~m}$, and $150 \mathrm{~m}$. If $L$ is the distance between the monitoring plane and the working face, then $L$ can be regarded as $90 \mathrm{~m}, 50 \mathrm{~m}$, $30 \mathrm{~m}, 10 \mathrm{~m},-10 \mathrm{~m}$, and $-50 \mathrm{~m}$, respectively.

As shown in Figure 11(a), the monitoring plane has not been affected by mining activities when the working face advances $10 \mathrm{~m}(L=90 \mathrm{~m})$; it is only affected by the lateral abutment stress. A small part of the coal seam floor has plastic failure under the peak value of lateral stress, and the failure depth is only $4 \mathrm{~m}$. With the continuous advance of the working face, the floor rock marked as area $\mathrm{A}$ is first destroyed under the superimposed influence of the advance abutment stress and the lateral abutment stress, and the 


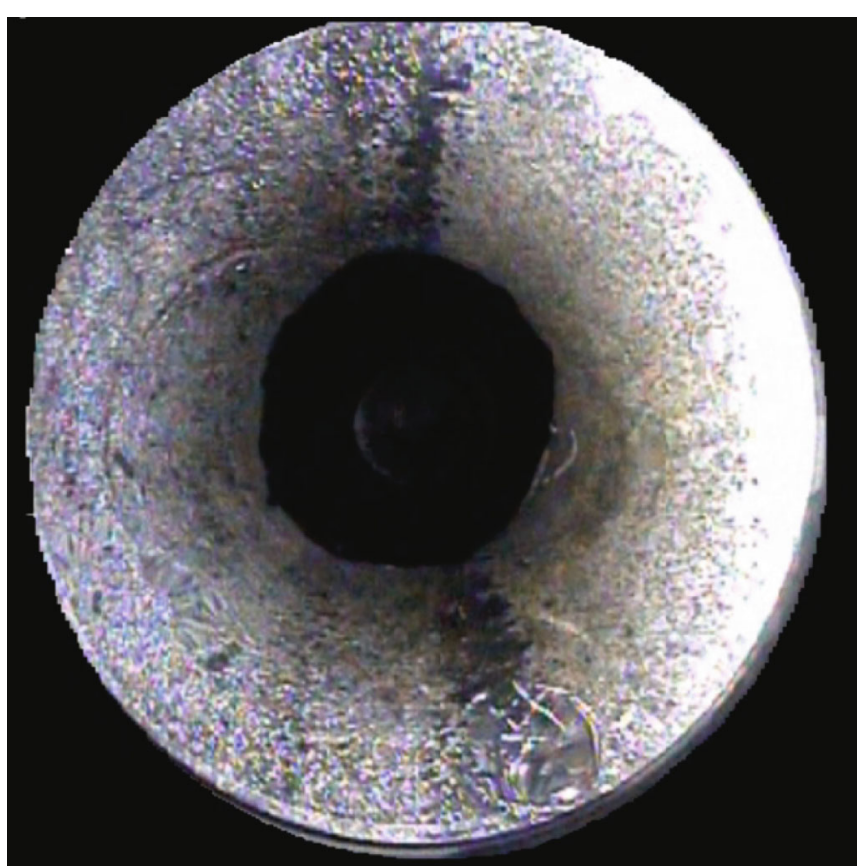

(a) $L=156 \mathrm{~m}$

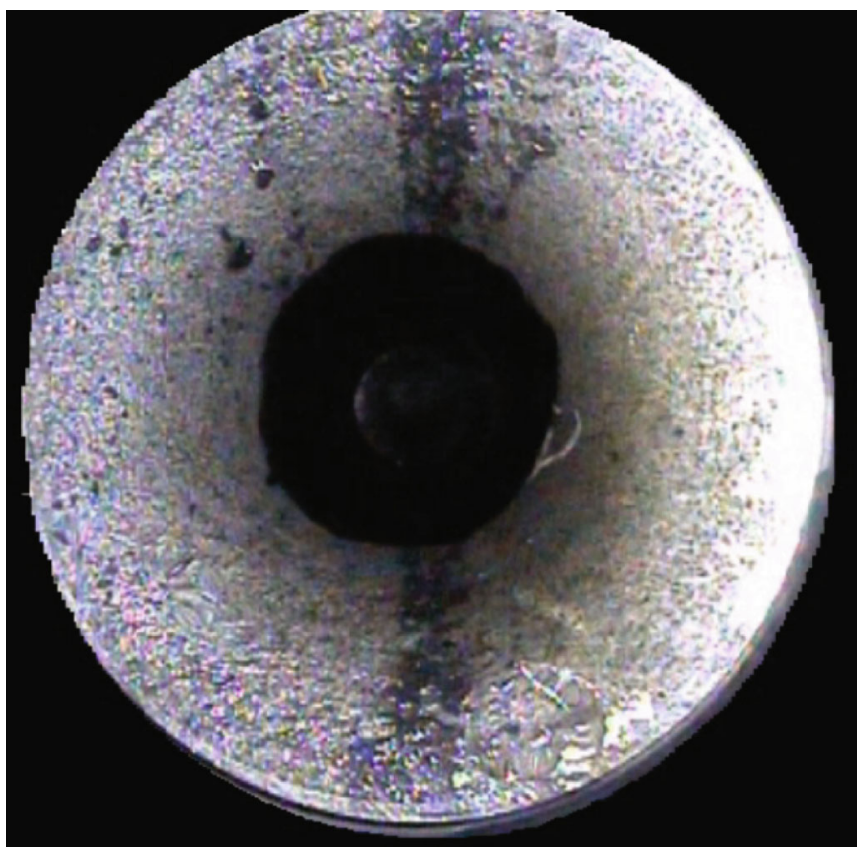

(c) $L=-16 \mathrm{~m}$

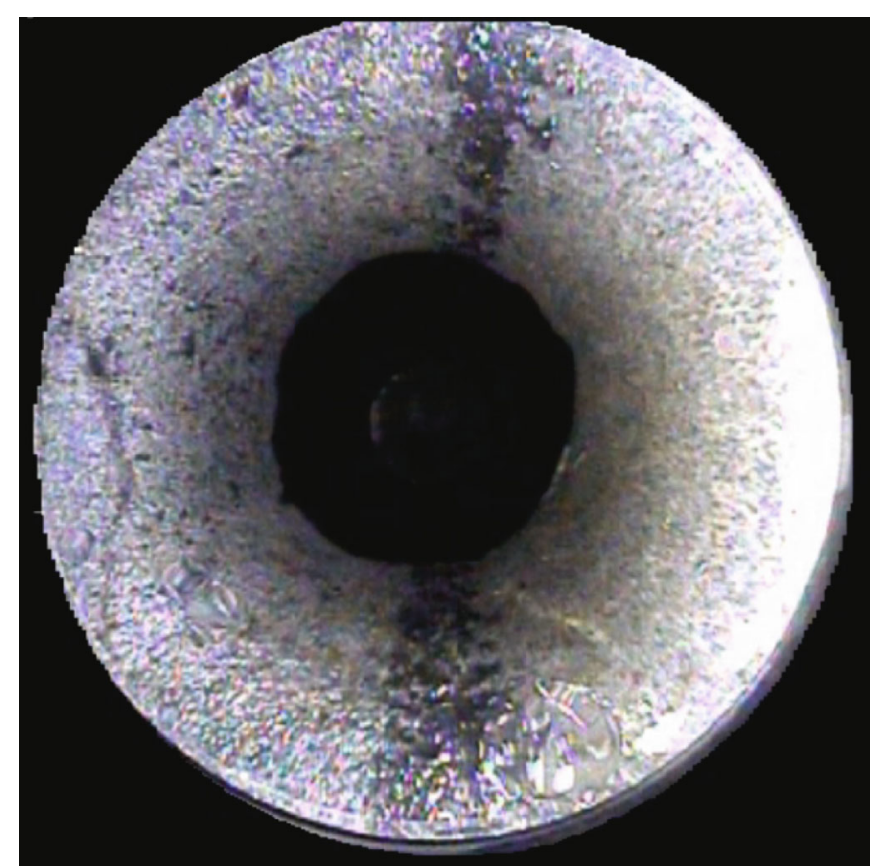

(b) $L=38 \mathrm{~m}$

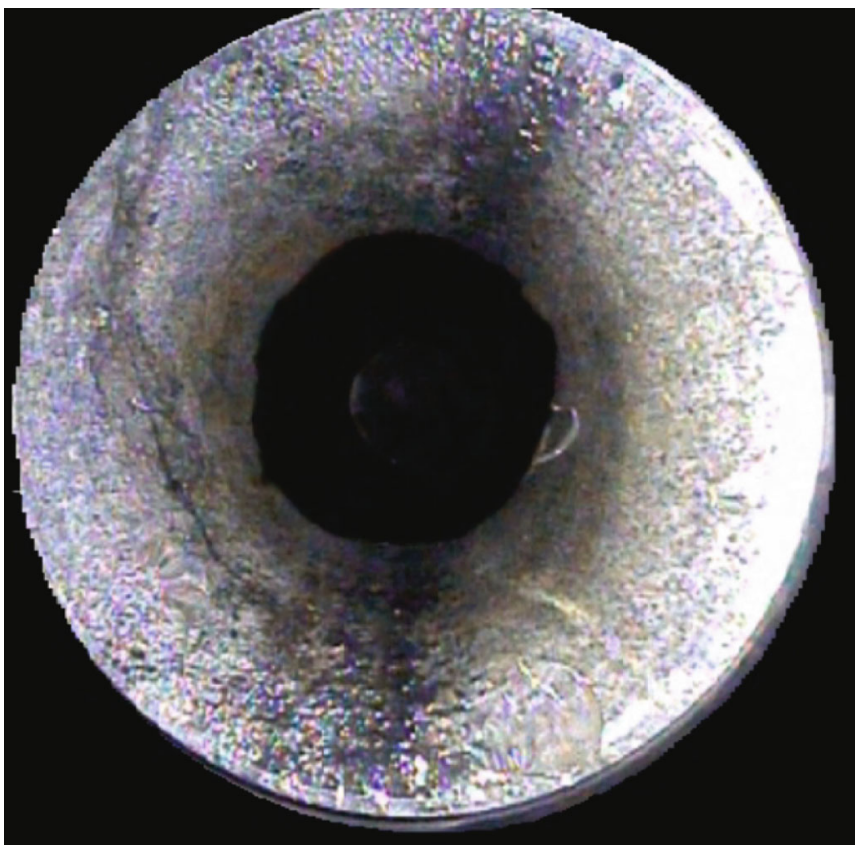

(d) $L=-60 \mathrm{~m}$

Figure 9: Image of damage and deformation at the vertical depth of $26-27 \mathrm{~m}$.

maximum failure depth is $22 \mathrm{~m}$ with $L=30 \mathrm{~m}$. However, the floor rock marked as area B is not destroyed. With the working face gradually approaching the monitoring plane, the influence of the advance stress on floor rock is greater and area B starts to plastically fail. When $L=10 \mathrm{~m}$, the maximum failure depth of the floor rock of area $\mathrm{A}$ is $26 \mathrm{~m}$, while that of area $B$ is $14 \mathrm{~m}$; the abutment stress decreases rapidly, and the floor rock around 10304 goaf changes from triaxial to biaxial, causing the rock plastic failure of area B to develop rapidly. Then, the rock failure depth of area A is unchanged when $L$
$=-10 \mathrm{~m}$, and the average failure depth of area B rises to $22 \mathrm{~m}$. Since then, the mining activities have little influence on the depth and scope of floor failure on the monitoring plane.

Through the aforementioned analyses, the floor rock of the island working face can be roughly divided into area A and area $\mathrm{B}$, according to the development characteristics and failure depth of the plastic zone of the floor. During the mining process, the floor rock of area $\mathrm{A}$ is first destroyed with the superimposing effect of the advance abutment stress and 


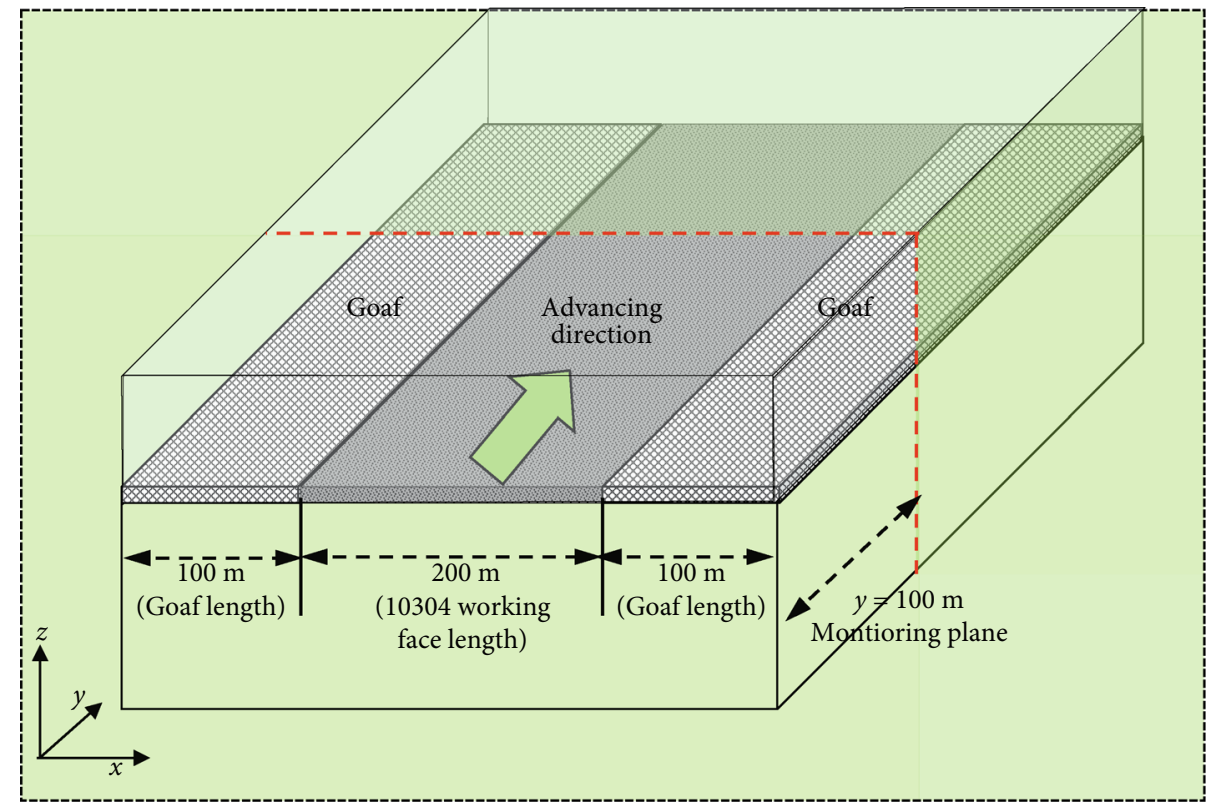

FIGURE 10: Layout of the working face and the monitoring plane.

TABLE 2: The geomechanical parameters of each stratum.

\begin{tabular}{|c|c|c|c|c|c|c|}
\hline Rock & $\underset{3}{\text { Density }}\left(\mathrm{g} \cdot \mathrm{cm}^{-}\right.$ & $\begin{array}{c}\text { Bulk modulus } \\
(\mathrm{GPa})\end{array}$ & $\begin{array}{c}\text { Shear modulus } \\
(\mathrm{GPa})\end{array}$ & $\begin{array}{c}\text { Cohesion } \\
(\mathrm{MPa})\end{array}$ & $\begin{array}{c}\text { Friction angle } \\
\left({ }^{\circ}\right)\end{array}$ & $\begin{array}{c}\text { Tensile strength } \\
(\mathrm{MPa})\end{array}$ \\
\hline $\begin{array}{l}\text { Medium } \\
\text { sandstone }\end{array}$ & 2750 & 3.1 & 2.7 & 6.2 & 32 & 3.6 \\
\hline Siltstone & 2600 & 2.6 & 1.6 & 4.7 & 30 & 2.5 \\
\hline 3\#coal & 1400 & 1.1 & 0.3 & 1.2 & 22 & 0.6 \\
\hline Mudstone & 2500 & 1.8 & 0.5 & 2.2 & 26 & 1.6 \\
\hline Limestone & 2800 & 8.4 & 5 & 13.2 & 36 & 5.5 \\
\hline
\end{tabular}

lateral abutment stress, which is earlier than area B. The plastic failure of the goaf floor presents an inverted saddle shape, and the maximum rock failure depth of area $A$ is $26 \mathrm{~m}$ while that of area B is $22 \mathrm{~m}$. The numerical simulation results are basically consistent with the measured results, indicating that the numerical simulation results are reliable; meanwhile, the limitation of the field measurement range is made up by methods of numerical simulation. Thus, the combination of the numerical simulation method and field measurement could more reflect comprehensively and accurately the $3 \mathrm{D}$ failure characteristics of the floor of the whole island working face affected by mining activities.

\section{Conclusion}

Using the strain sensing method and borehole imaging technology to observe and analyze the failure deformation law of the floor during the mining process of panel 10304 in the Xinglongzhuang coal mine, the following conclusions can be drawn:

(1) According to the correlation analysis between the strain test results and the borehole image, it can be determined that the depth of the floor damage is approximately $23 \mathrm{~m}$ during the advancement of panel 10304. The test results can provide a reliable basis for the safe mining of other working faces in the upper part of the aquifer in the Xinglongzhuang coal mine

(2) The degree of deformation and failure of the rock mass at different depths of the floor during the advancement of the working face decreases with increasing depth. The deformation damage increases with the working face advancement until a certain distance is reached at the same depth

(3) By means of the strain increment of each sensor probe and the borehole image at different positions, the influence range of the advancing abutment pressure in front of the coal wall and the influence degree of the advancement and lag can be reflected. The successful application of the integrated measurement method provides a new idea for studying the influence range of mining pressure and the influence degree of advancement and lag

(4) Numerical simulation results show that the floor rock of area A is first destroyed firstly due to the superimposed influence of the advance abutment stress and 


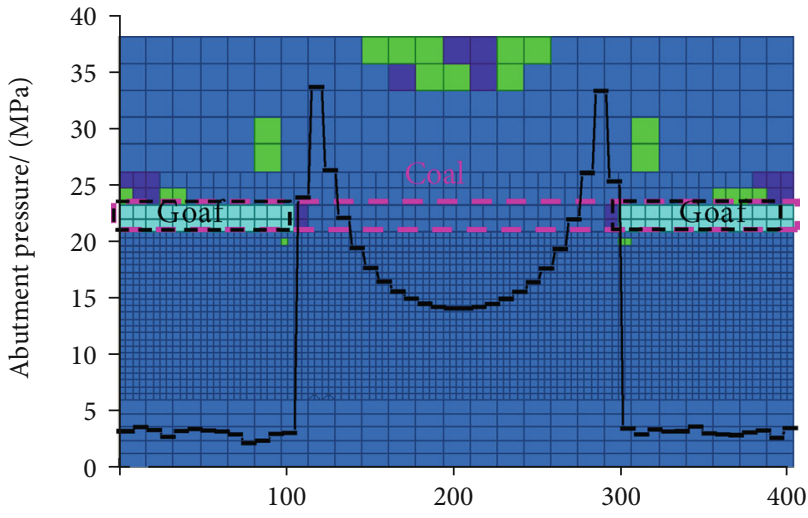

Face length/ (m)

Zone

Plane: on

Colorby: state-average

None

Shear-n shear-p

Shear-p

Shear-p tension- $p$

Shear-p tension- $p$ volume-n volume-

Shear-p tension-p volume-p

(a) $L=90 \mathrm{~m}$

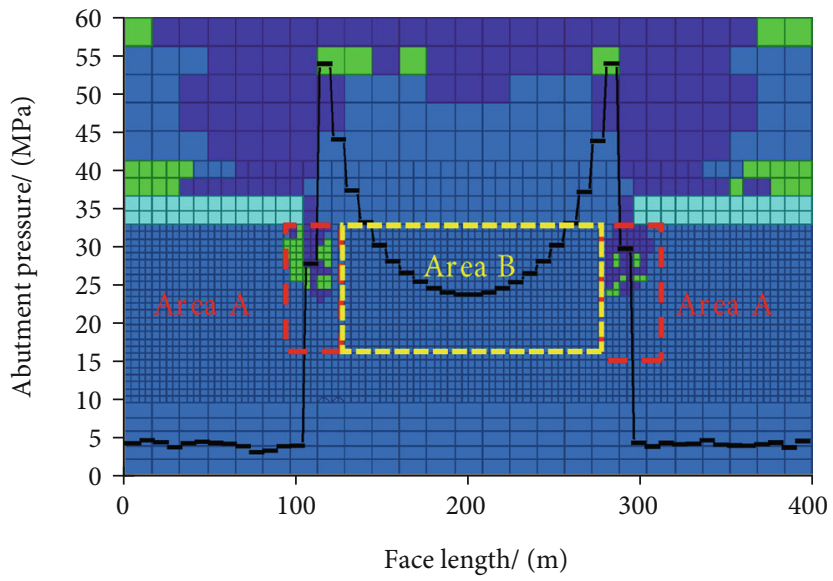

Zone

Plane: on

Colorby: state-average

None

Shear-n shear-p

Shear-p

Shear-p tension- $p$

Shear-p tension- $p$ volume-n volume-p

Shear-p tension-p volume-p

(c) $L=30 \mathrm{~m}$

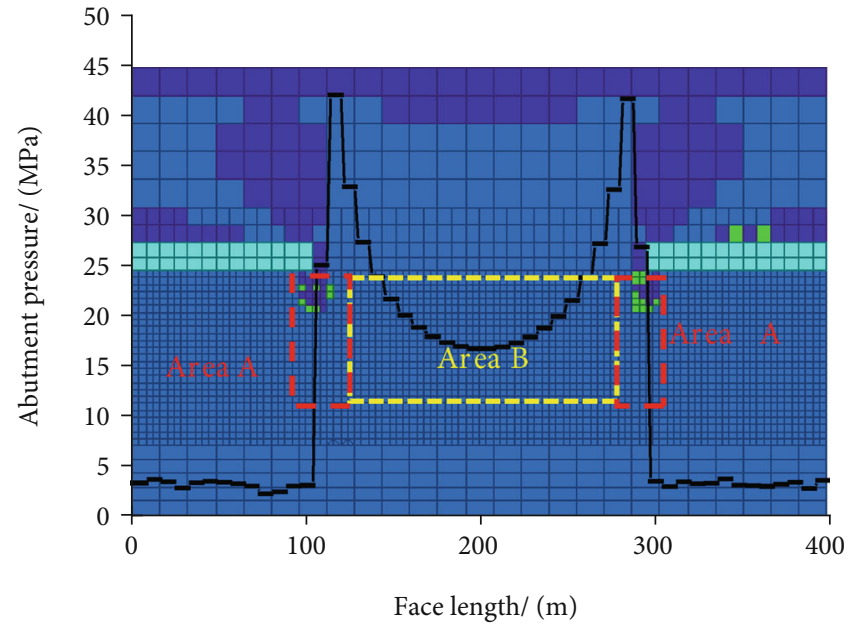

(b) $L=50 \mathrm{~m}$

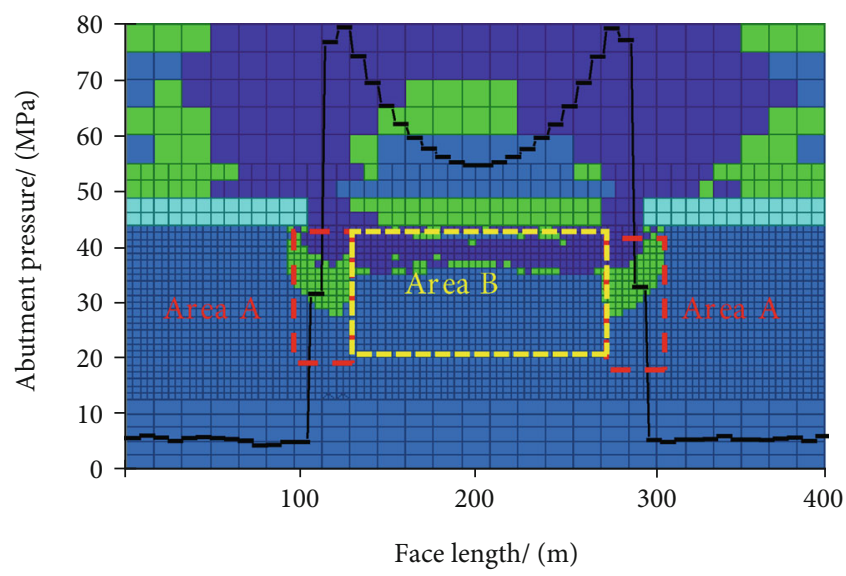

(d) $L=10 \mathrm{~m}$

FIgURE 11: Continued. 

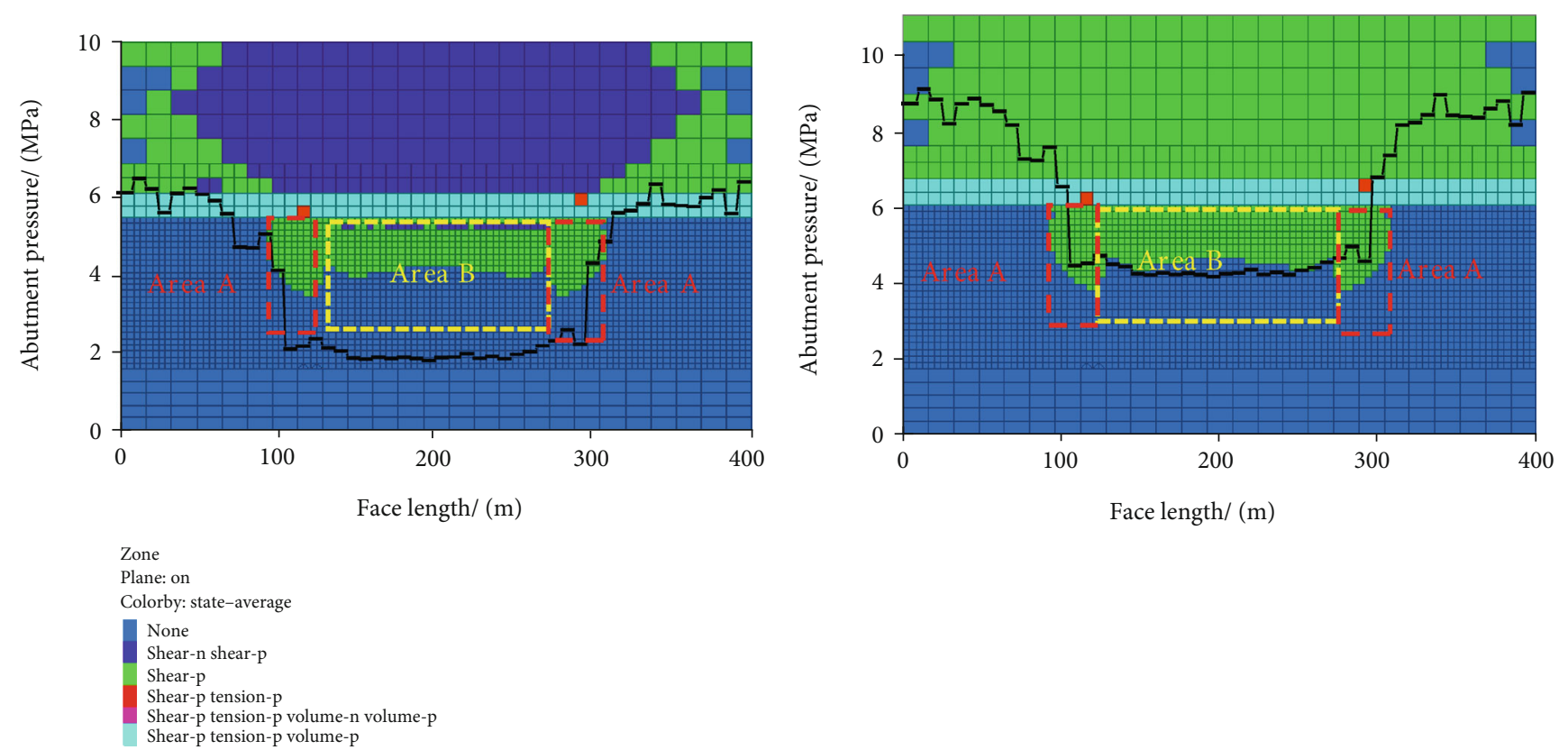

(e) $L=-10 \mathrm{~m}$

(f) $L=-50 \mathrm{~m}$

FIGURE 11: Abutment stress distribution and development of the plastic zone with plane $y=100 \mathrm{~m}$.

the lateral abutment stress, which is earlier than area B. The plastic failure of the goaf floor presents an inverted saddle shape, and the maximum rock failure depth of area A is $26 \mathrm{~m}$ while that of area B is $22 \mathrm{~m}$. The failure shape and failure depth are consistent with the results of field measurements

(5) On the basis that the simulation results of failure characteristics of the floor are consistent with the field measurement results, the combination of the numerical simulation method and field measurement could more reflect comprehensively and accurately the 3D failure characteristics of the floor of the whole island working face in the mining process

\section{Data Availability}

The data used to support the findings of this study are available from the corresponding author upon request.

\section{Conflicts of Interest}

The authors declare no conflicts of interest.

\section{Acknowledgments}

The study was funded by the National Natural Science Foundation of China (No. 51804182), Second Batch of Cooperative Education Projects of Ministry of Education in 2019 (No. 201902153001), Shandong Provincial Natural Science Foundation (No. ZR2019BEE065), Key R \& D plan of Shandong Province (No. 2019SDZY034-1), and Support Plan for Outstanding Youth Innovation Team in Shandong Colleges and Universities (No. 2019KJG007).

\section{References}

[1] L. Q. Shi, M. Qiu, Y. Wang, X. Qu, and T. Liu, "Evaluation of water inrush from underlying aquifers by using a modified water-inrush coefficient model and water-inrush index model: a case study in Feicheng coalfield, China," Hydrogeology Journal, vol. 27, no. 6, pp. 2105-2119, 2019.

[2] S. C. Zhang, W. Guo, Y. Li, W. Sun, and D. Yin, "Experimental simulation of fault water inrush channel evolution in a coal mine floor," Mine Water and Environment, vol. 36, no. 3, pp. 443-451, 2017.

[3] S. L. Liu, W. Liu, Z. Huo, and W. Song, "Early warning information evolution characteristics of water inrush from floor in underground coal mining," Arabian Journal of GeoSciences, vol. 12, no. 2, 2019.

[4] P. Wang, L. S. Jiang, P. Q. Zheng, G. P. Qin, and C. Zhang, "Inducing mode analysis of rock burst in fault-affected zone with a hard-thick stratum occurrence," Environmental Earth Sciences, vol. 78, no. 15, p. 467, 2019.

[5] H. Liu, B. Yu, J. Liu, and T. Wang, "Investigation of impact rock burst induced by energy released from hard rock fractures," Arabian Journal of Geosciences, vol. 12, no. 12, p. 381, 2019.

[6] P. Wang, L. Jiang, J. Jiang, P. Zheng, and W. Li, "Strata behaviors and rock burst-inducing mechanism under the coupling effect of a hard, thick stratum and a normal fault," International Journal of Geomechanics, vol. 18, no. 2, 2018.

[7] P. Wang, H. Jia, and P. Zheng, "Sensitivity analysis of bursting liability for different coal-rock combinations based on their inhomogeneous characteristics," Geomatics, Natural Hazards and Risk, vol. 11, no. 1, pp. 149-159, 2020.

[8] Y. Wang, M. He, J. Yang et al., "Case study on pressure-relief mining technology without advance tunneling and coal pillars in longwall mining," Tunnelling Underground Space Technology., vol. 97, 2020. 
[9] Y. Li, J. Yang, Z. Pan, and W. Tong, "Nanoscale pore structure and mechanical property analysis of coal: an insight combining AFM and SEM images," Fuel, vol. 260, p. 116352, 2020.

[10] S. Zhao, Y. Li, Y. Wang, Z. Ma, and X. Huang, "Quantitative study on coal and shale pore structure and surface roughness based on atomic force microscopy and image processing," Fuel, vol. 244, pp. 78-90, 2019.

[11] D. H. Cai, C. W. Dong, L. C. Peng, and B. H. Xu, "The analytic estimation of floor failure depth under the arch structure of overlyingstrata of coal seam," Journal of Shandong University of Science and Technology, vol. 24, no. 2, pp. 13-16, 2005.

[12] L. Q. Shi, D. J. Xu, M. Qiu, X. Jing, and H. H. Sun, "Improved on the formula about the depth of damaged floor in working area," Journal of China Coal Society, vol. 38, pp. 299-303, 2013.

[13] W. T. Liu, D. Mu, X. Xie, L. Yang, and D. Wang, "Sensitivity analysis of the main factors controlling floor failure depth and a risk evaluation of floor water inrush for an inclined coal seam," Mine Water and Environment, vol. 37, no. 3, pp. 636-648, 2018.

[14] X. G. Yu, J. Han, L. Shi, Y. Wang, and Y. Zhao, “Application of a BP neural network in predicting destroyed floor depth caused by underground pressure," Environmental Earth Sciences, vol. 76, no. 15, p. 535, 2017.

[15] S. H. Liu, W. T. Liu, and J. J. Shen, "Stress evolution law and failure characteristics of mining floor rock mass above confined water," KSCE Journal of Civil Engineering, vol. 21, no. 7, pp. 2665-2672, 2017.

[16] W. C. Song, Z. Z. Liang, W. T. Liu, and C. B. Zhao, "Theoretical analysis and experimental study on failure characteristics and stability of stope floor," Chinese Journal of Rock Mechanics and Engineering, vol. 11, pp. 2208-2218, 2019.

[17] Y. Li, W. Xu, P. Wu, and S. Meng, "Dissolution versus cementation and its role in determining tight sandstone quality: a case study from the Upper Paleozoic in northeastern Ordos Basin, China," Journal of Natural Gas Science and Engineering, vol. 78, p. 103324, 2020.

[18] J. L. Cai, M. Tu, and W. S. Xu, "Failure depth of a floor of a fully mechanized working face when passing a collapse column," Advances in Civil Engineering, vol. 2018, Article ID 9406839, 9 pages, 2018.

[19] S. Y. Zhu, Z. Q. Jiang, K. J. Zhou, G. Q. Peng, and C. W. Yang, "The characteristics of deformation and failure of coal seam floor due to mining in Xinmi coal field in China," Bulletin of Engineering Geology and the Environment, vol. 73, no. 4, pp. 1151-1163, 2014.

[20] W. Han, G. X. Li, Z. H. Sun, H. J. Luan, C. Z. Liu, and X. L. Wu, "Numerical investigation of a foundation pit supported by a composite soil nailing structure," Symmetry, vol. 12, no. 2, p. 252, 2020.

[21] W. Wei, "Study on the depth of floor damage caused by mine pressure in Feicheng mining area," China Coal, vol. 31, no. 9, pp. 55-57, 2005.

[22] H. Zhou, C. K. Qu, D. W. Hu et al., "In situ monitoring of tunnel deformation evolutions from auxiliary tunnel in deep mine," Engineering Geology, vol. 221, pp. 10-15, 2017.

[23] H. Z. Wang, D. S. Zhang, X. F. Wang, and W. Zhang, "Visual exploration of the spatiotemporal evolution law of overburden failure and mining-induced fractures: a case study of the Wangjialing coal mine in China," Minerals, vol. 7, no. 3, p. 35, 2017.

[24] W. P. Liu, S. S. Saab, J. Rostami, and A. Ray, "Improving the capability of detecting joints and fractures in rock mass from roof bolt drilling data by using wavelet analysis," International Journal of Oil Gas and Coal Technology, vol. 30, no. 5, 2016.

[25] L. S. Jiang, P. Wang, P. Q. Zheng, H. J. Luan, and C. Zhang, "Influence of different advancing directions on mining effect caused by a fault," Advances in Civil Engineering, vol. 2019, Article ID 7306850, 10 pages, 2019.

[26] Z. H. Qiu, L. Tang, B. H. Zhang, and Y. P. Guo, "In situ calibration of and algorithm for strain monitoring using four-gauge borehole strainmeters (FGBS)," Journal of Geophysical Research: Solid Earth, vol. 118, no. 4, pp. 1609-1618, 2013.

[27] Q. Zhang, J. X. Zhang, T. Kang, Q. Sun, and W. K. Li, “Mining pressure monitoring and analysis in fully mechanized backfilling coal mining face-a case study in Zhai Zhen coal mine," Journal of Central South University, vol. 22, no. 5, pp. 19651972, 2015.

[28] H. Liu, J. Dai, J. Q. Jiang, P. Wang, and J. Q. Yang, “Analysis of overburden structure and pressure-relief effect of hard roof blasting and cutting," Advances in Civil Engineering, vol. 2019, Article ID 1354652, 14 pages, 2019.

[29] N. Zhang, N. C. Zhang, C. L. Han, D. Y. Qian, and F. Xue, "Borehole stress monitoring analysis on advanced abutment pressure induced by longwall mining," Arabian Journal of Geosciences, vol. 7, no. 2, pp. 457-463, 2014.

[30] P. Wang, L. Jiang, X. Li, G. Qin, and E. Wang, "Physical simulation of mining effect caused by a fault tectonic," Arabian Journal of Geosciences, vol. 11, no. 23, 2018.

[31] X. Y. Liu, Z. Y. Wang, H. F. Fang, S. M. Huang, and L. Wang, "Analysis of 4-component borehole strain observation based on strain invariant," Chinese Journal of Geophysics-Chinese Edition., vol. 5, no. 10, pp. 3332-3346, 2014.

[32] H. F. Duan, "Study on mining deformation of floor and evaluation method of water inrush mining above confined aquifer," Ph.D. thesis, China University of Mining and Technology, Beijing, 2012.

[33] W. F. Gao, L. Shi, J. Han, and P. Zhai, "Dynamic monitoring of water in a working face floor using 2D electrical resistivity tomography (ERT)," Mine Water and Environment, vol. 37, no. 3, pp. 423-430, 2018.

[34] S. Zhang, X. Wang, G. Fan, D. Zhang, and C. Jianbin, "Pillar size optimization design of isolated island panel gob-side entry driving in deep inclined coal seam-case study of Pingmei No. 6 coal seam," Journal of Geophysics and Engineering, vol. 15, no. 3, pp. 816-828, 2018.

[35] G. J. Liu, Z. L. Mu, J. J. Chen, J. Yang, and J. L. Cao, "Rock burst risk in an island longwall coal face by stress field," Geosciences Journal, vol. 22, no. 4, pp. 609-622, 2018.

[36] D. U. A. N. Hongfei, J. I. A. N. G. Zhenquan, and R. Zhang, "Field measurement and simulation research on failure depth of fully mechanized thin coal seam floor in Yangcun coal mine," Journal of china coal society, vol. 36, no. S1, pp. 13$17,2011$. 